\title{
ECHOCARDIOGRAPHIC EVALUATION IN CHRONIC OBSTRUCTIVE PULMONARY DISEASE PATIENTS AND ITS RELATION WITH THE SEVERITY OF DISEASE
}

\author{
Sukhdeep Kaur1, Ashok Khurana2, Preeti Singh Dhoat ${ }^{3}$, Gurinder Mohan ${ }^{4}$
}

1 Junior Resident, Department of General Medicine, Sri Guru Ram Das Institute of Medical Sciences and Research (SGRDIMSR), Amritsar. 2 Professor, Department of General Medicine, Sri Guru Ram Das Institute of Medical Sciences and Research (SGRDIMSR), Amritsar. ${ }^{3}$ Associate Professor, Department of General Medicine, Sri Guru Ram Das Institute of Medical Sciences and Research (SGRDIMSR), Amritsar.

${ }^{4}$ Professor and HOD, Department of General Medicine, Sri Guru Ram Das Institute of Medical Sciences and Research (SGRDIMSR), Amritsar.

\section{ABSTRACT}

\section{BACKGROUND}

Chronic Obstructive Pulmonary Disease (COPD) has considerable effects on cardiac functions including those of the right ventricle, left ventricle and pulmonary blood vessels. Most of the increased mortality associated with COPD is due to cardiac involvement. Echocardiography provides a rapid, non-invasive, portable and accurate method to evaluate the cardiac changes.

The aim of this study was to assess the cardiac changes secondary to COPD by echocardiography and to find out the correlation between echocardiographic findings and severity of COPD.

\section{MATERIALS AND METHODS}

A total of 50 patients of COPD were selected and staged by pulmonary function test and evaluated by echocardiography.

\section{RESULTS}

The number of patients with mild, moderate, severe and very severe COPD in our study were $2 / 50=4 \%, 14 / 50=28 \%, 29 / 50=58 \%$ and $5 / 50=10 \%$, respectively. On echocardiographic evaluation of COPD, $24 \%$ cases had normal echocardiographic parameters. Pulmonary Hypertension (PH), which is defined as Systolic Pulmonary Arterial Pressure (sPAP) > 30 mmHg was observed in 35/50 $(70 \%)$ cases in which prevalence of mild, moderate and severe PH were $0 / 2=0 \%, 7 / 14=50 \%, 23 / 29=79.3 \%$ and $5 / 5=100 \%$, respectively. Right ventricle was enlarged in ECHO in 23/50 $=46 \%$ of patients. Right atrium was enlarged in ECHO in $7 / 50=14 \%$ of patients. Measurable Tricuspid Regurgitation (TR) was observed in 36/50 cases $72 \%$.

\section{CONCLUSION}

Prevalence of cardiac dysfunction increases as the severity of COPD increases. It is recommended that echocardiography should be done early in all cases of COPD to diagnose the cardiac complications of COPD, so that early interventions can be undertaken in order to improve quality of life and decrease mortality and morbidity in COPD patients.

\section{KEYWORDS}

Chronic Obstructive Pulmonary Disease, Echocardiography, Pulmonary Hypertension.

HOW TO CITE THIS ARTICLE: Kaur S, Khurana A, Dhoat PS, et al. Echocardiographic evaluation in chronic obstructive pulmonary disease patients and its relation with the severity of disease. J. Evolution Med. Dent. Sci. 2016;5(101):7405-7408, DOI: $10.14260 /$ Jemds/2016/1676

\section{BACKGROUND \\ Chronic Obstructive Pulmonary Disease is a disease state characterised by the presence of airflow obstruction due to chronic bronchitis or emphysema, the airflow obstruction is generally progressive and may be accompanied by airway hyper-reactivity and may be partially reversible.[1] Chronic bronchitis is defined as the presence of chronic productive cough on most of the days for at least 3 months, for at least 2 consecutive years.[2] Emphysema is defined as abnormal permanent enlargement of distal air spaces, distal to terminal}

Financial or Other, Competing Interest: None.

Submission 27-11-2016, Peer Review 10-12-2016,

Acceptance 12-12-2016, Published 19-12-2016.

Corresponding Author:

Sukhdeep Kaur,

Junior Resident

Department of General Medicine,

Amritsar, Street No. 9,

Shahid Balwinder Nagar, Faridkot-151203,

Punjab, India.

E-mail: sukhdeepkaur6@gmail.com

DOI: $10.14260 /$ jemds/2016/1676

\section{(c) $(1)$}

bronchioles, accompanied by destruction of their walls and without obvious fibrosis. [3]

COPD is a leading cause of death and disability worldwide. In India, COPD is the second most common lung disorder after pulmonary tuberculosis and remains a major public health problem. Risk factors for COPD include both host factors like alpha-1 antitrypsin deficiency and environmental exposure like tobacco smoke and the disease usually arises from an interaction between these 2 types of factors. Diagnosis of COPD is confirmed by an objective measurement of airflow obstruction by spirometry. COPD has been classified by severity according to GOLD guidelines into 4 stages - Stage I: Mild COPD $\left(\mathrm{FEV}_{1} / \mathrm{FVC}<0.7, \mathrm{FEV}_{1} \geq 80 \%\right.$ predicted), Stage II: moderate COPD $\left(\mathrm{FEV}_{1} / \mathrm{FVC}<0.7, \mathrm{FEV}_{1} \geq 50 \%\right.$ but $<80 \%$ predicted), Stage III: Severe COPD $\left(\mathrm{FEV}_{1} / \mathrm{FVC}<0.7, \mathrm{FEV}_{1} \geq\right.$ $30 \%$ but $<50 \%$ predicted), Stage IV: Very severe COPD: $\left(\mathrm{FEV}_{1} / \mathrm{FVC}<0.7, \mathrm{FEV}_{1}<30 \%\right.$ predicted $)$.

COPD is associated with significant cardiac manifestations. Cardiovascular disease accounts for approximately $50 \%$ of all hospitalisation and nearly one-third of all deaths of COPD patients, if FEV $1>50 \%$ of the predicted. ${ }^{[4]}$ In more advanced COPD cases, cardiovascular disease account for $20 \%-25 \%$ of 
all deaths.[5] The cardiac manifestations of COPD are numerous. Impairment of right ventricular function and pulmonary blood vessels are well known to complicate the clinical course of COPD and co-relate inversely with survival. Significant structural changes occur in the pulmonary circulation in patients with COPD. The presence of hypoxaemia and chronic ventilator insufficiency is associated with early evidence of intimal thickening and medial hypertrophy in the smaller branches of the pulmonary arteries. Coupled with these pathological changes are pulmonary vasoconstriction arising from the presence of alveolar hypoxaemia, destruction of pulmonary vascular bed, changes in intrinsic pulmonary vasodilator substances such as decrease in prostacyclin synthase ( $\left.\mathrm{PGI}_{2} \mathrm{~S}\right)$, decrease in endothelial nitric oxide synthase (eNOS) and increase in ET1 (endothelin1) leading to remodeling, increase in blood viscosity and alteration in respiratory mechanics. All these lead to a significant increase in pulmonary vascular resistance, the consequence of which is pulmonary hypertension. Severe pulmonary hypertension increases right ventricular after load with a corresponding increase in right ventricular work, which results in uniform hypertrophy of the right ventricle. In patients with COPD, hypoxic vasoconstriction is associated with not only right ventricular hypertrophy but also right ventricular dilatation which eventually leads to clinical syndrome of right heart failure with systemic congestion and inability to adapt right ventricular output to the peripheral demand on exercise. Thus, chronic alveolar hypoxia induced vasoconstriction increases pulmonary vascular resistance leading to pulmonary hypertension and thus cor pulmonale.

Although, the true prevalence of pulmonary hypertension in COPD is unknown, an elevation of pulmonary arterial pressure is reported to occur in $20 \%-90 \%$ of patients when measured by right heart catheterisation with some evidence that pulmonary haemodynamic worsens with worsening airflow obstruction. Pulmonary hypertension in COPD progresses slowly and occurs in mild as well as severe forms of the disease. The incidence of pulmonary hypertension is directly proportional to severity of COPD. Right ventricular dysfunction is reported to occur in up to $50 \%$ of the patients with moderate-to-severe COPD and portends a higher mortality rate. Its recognition and treatment may lead to prolonged survival and improved quality of life.[6]

Thus, COPD affects pulmonary blood vessels, right ventricle as well as left ventricle leading to development of pulmonary hypertension, cor-pulmonale, right ventricular dysfunction and left ventricular dysfunction too. Using invasive measures, Pulmonary Hypertension ( $\mathrm{PH}$ ) is defined as an increase in mean Pulmonary Arterial Pressure (PAP) to $>25 \mathrm{mmHg}$ at rest as measured by Right Heart Catheterisation (RHC).[7] Echocardiography provides a rapid, non-invasive, portable and accurate method to evaluate pulmonary arterial pressure, right ventricle function, right ventricular filling pressure, tricuspid regurgitation, left ventricular function and valvular function. ${ }^{[8]}$ The studies have confirmed the close correlation of echocardiography estimated pulmonary arterial pressure with invasive measurements (right heart catheterisation) in patients with Chronic Obstructive Pulmonary Disease (COPD). In view of the adverse effects of pulmonary arterial hypertension on morbidity and mortality, routine echocardiography in patients with COPD may be warranted. Echocardiography helps in early detection of cardiac complications in COPD cases giving opportunity for early interventions.

COPD patients probably are not usually assessed by ECHO in routine medical practice, particularly in developing countries like India. Therefore, the present study consisting of pulmonary and cardiac evaluation of fifty COPD patients was conducted to evaluate the diagnostic value of ECHO findings among the COPD patients, so as to identify cardiac manifestations of COPD and their relationship with severity of COPD so that early intervention can be undertaken in order to improve quality of life and decrease mortality and morbidity in COPD patients.

\section{MATERIALS AND METHODS}

The study was conducted on 50 patients with COPD, who attended OPD and indoor of SGRDIMSAR, Amritsar. The COPD cases were diagnosed by clinical history, general physical examination, detailed systemic examination and necessary investigations. All the patients were investigated by spirometry and diagnosed and classified according to the GOLD guidelines. Then all the patients of COPD were subjected to resting two-dimensional transthoracic Doppler echocardiography. Echocardiography was done to assess the pericardium valvular anatomy and function, left and right side chamber size and cardiac function. Tricuspid regurgitant flow was identified by colour flow Doppler technique and maximum jet velocity was measured by continuous wave Doppler without the use of intravenous contrast. Right ventricular systolic pressure was estimated based on the modified Bernoulli equation and considered to be equal to SPAP in the absence of right ventricular outflow obstruction. $\operatorname{sPAP}(\mathrm{mmHg})=$ right ventricular systolic pressure $=$ Transtricuspid Pressure Gradient (TTPG) + Right Atrial Pressure (RAP), where transtricuspid gradient is $4 \mathrm{v} 2(\mathrm{v}=$ peak velocity of tricuspid regurgitation).

Pulmonary hypertension was defined in the study as sPAP $\geq 30 \mathrm{mmHg}$. Right ventricular dimensions were measured by M-Mode ECHO and right ventricular dilatation or cor pulmonale said to be present when it exceeded the normal range of $0.9-2.6 \mathrm{~cm}$. Left ventricular function was assessed by using Ejection Fraction (EF) measure of how much end diastolic value is ejected from left ventricle with each contraction. In ECHO, following parameters were evaluated: RV enlargement, Tricuspid regurgitation, RA enlargement, Pulmonary arterial hypertension, LV function as assessed by LV ejection fraction. Statistical analysis was performed using Spearman's correlation coefficient and relationship between echocardiographic findings and severity of disease was observed.

\section{RESULTS}

In our study, mean age was $59.52 \pm 12.53$ years with the range being 22 - 85 years. Males formed $70 \%$ of patients with Female: male sex ratio of $1: 2.33$. The study group had 26 patients (52\%) who were smokers, which show that smoking is an important predisposing factor in development of COPD; 16 patients (32\%) had some sort of environmental exposure in the form of tobacco smoke, heavy exposure to occupational dusts and chemicals, etc.

The study group was subdivided based on the severity of COPD according to GOLD guidelines. The group was divided into Stage I: Mild COPD (FEV1 $\geq 80 \%$ ), Stage II: Moderate COPD 
$\left(\mathrm{FEV}_{1} \geq 50 \%\right.$, but $<80 \%$ ), Stage III: Severe COPD (FEV $1 \geq 30 \%$, but $<50 \%)$ and Stage IV: Very severe COPD ( $\left.\mathrm{FEV}_{1}<30 \%\right)$. The number of patients with mild, moderate, severe and very severe COPD in our study were $2 / 50=4 \%, 14 / 50=28 \%$, $29 / 50=58 \%$ and $5 / 50=10 \%$, respectively.

The study group was also divided into subgroups depending upon the duration of the disease. The duration of the disease was determined on the basis of retrospective history and any medical records available. Majority of patients in the study group fell in the disease duration group of $4-8$ years. The range of duration of disease was $4-20$ years with the mean duration being $11.08 \pm 4.83$ years.

Normal echocardiography was seen in $24 \%$ cases in our study. In the analysis of echocardiographic findings, our study showed $70 \%$ of the patients had echocardioghaphic evidence of pulmonary arterial hypertension. Frequency of PAH in ECHO in mild, moderate, severe and very severe COPD was $0 / 2$ $=0 \%, 7 / 14=50 \%, 23 / 29=79.3 \%$ and $5 / 5=100 \%$, respectively. There was statistically significant correlation between severity of COPD and PAH with correlation coefficient of +0.434 and $p$ value $<0.05$. Table 1 shows comparison of $\mathrm{PAH}$ in ECHO according to severity of disease.

Cor pulmonale comprising of right ventricular enlargement was found in ECHO in $23 / 50=46 \%$ of patients. Frequency of RV enlargement in ECHO in mild, moderate, severe and very severe COPD was $0 / 2=0 \%, 4 / 14=28.6 \%$, $14 / 29=48.3 \%$ and $5 / 5=100 \%$, respectively. Spearman's correlation coefficient between severity of COPD and prevalence of RV enlargement was +0.395 and $p$ value was 0.005 . So as the severity of COPD increased, prevalence of cor pulmonale/RV enlargement also increased significantly. Table 2 shows comparison of RV size in ECHO according to severity of disease.

Right atrial enlargement was present in $14 \%$ patients with frequency in mild, moderate, severe and very severe COPD in $0 / 2=0 \%, 1 / 14=7.1 \%, 3 / 29=10.3 \%$ and $3 / 5=60 \%$, respectively. Prevalence of right atrial enlargement also correlated significantly with severity of COPD with correlation coefficient of +0.307 and $p$ value of $<0.05$. Table 3 shows comparison of RA size in ECHO according to severity of disease.

TR was present in ECHO in $36 / 50=72 \%$ of patients. Frequency of TR in ECHO in mild, moderate, severe and very severe COPD was $0 / 2=0 \%, 8 / 14=57.1 \%, 23 / 29=79.3 \%$ and $5 / 5=100 \%$, respectively. On correlating presence of TR with severity of COPD, statistically significant positive correlation was found with spearman's correlation coefficient of +0.387 and $p$ value of $<0.05$, i.e. as severity of COPD increased prevalence of tricuspid regurgitation also increased significantly. Table 4 shows comparison of TR in ECHO according to severity of disease.

\begin{tabular}{|c|c|c|c|c|c|}
\hline \multirow{2}{*}{ Severity } & \multicolumn{2}{|c|}{ PAH Present } & \multicolumn{2}{|c|}{ PAH Absent } & \multirow{2}{*}{ Total } \\
\cline { 2 - 5 } & No. & \% Age & No. & \% Age & \\
\hline I & 0 & 0 & 2 & 100 & 2 \\
\hline II & 7 & 50 & 7 & 50 & 14 \\
\hline III & 23 & 79.3 & 6 & 20.7 & 29 \\
\hline IV & 5 & 100 & 0 & 0 & 5 \\
\hline Table 1. Comparison of PAH in ECHO According to \\
Severity of Disease \\
\hline
\end{tabular}

\begin{tabular}{|c|c|c|c|c|c|}
\hline \multirow{2}{*}{ Severity } & \multicolumn{2}{|c|}{ Normal } & \multicolumn{2}{c|}{ Enlarged } & \multirow{2}{*}{ Total } \\
\cline { 2 - 5 } & No. & \% Age & No. & \% Age & \\
\hline I & 2 & 100 & 0 & 0 & 2 \\
\hline II & 10 & 71.4 & 4 & 28.6 & 14 \\
\hline III & 15 & 51.7 & 14 & 48.3 & 29 \\
\hline IV & 0 & 0 & 5 & 100 & 5 \\
\hline Table 2. Comparison of RV Size in ECHO According to \\
Severity of Disease \\
\hline
\end{tabular}

\begin{tabular}{|c|c|c|c|c|c|}
\hline \multirow{2}{*}{ Severity } & \multicolumn{2}{|c|}{ Normal } & \multicolumn{2}{c|}{ Enlarged } & \multirow{2}{*}{ Total } \\
\cline { 2 - 5 } & No. & \% Age & No. & \% Age & \\
\hline I & 2 & 100 & 0 & 0 & 2 \\
\hline II & 13 & 92.9 & 1 & 7.1 & 14 \\
\hline III & 26 & 89.7 & 3 & 10.3 & 29 \\
\hline IV & 2 & 40 & 3 & 60 & 5 \\
\hline
\end{tabular}

Table 3. Comparison of RA Size in ECHO According to Severity of Disease

\begin{tabular}{|c|c|c|c|c|c|}
\hline \multirow{2}{*}{ Severity } & \multicolumn{2}{|c|}{ Yes } & \multicolumn{2}{|c|}{ No } & \multirow{2}{*}{ Total } \\
\cline { 2 - 5 } & No. & \% Age & No. & \% Age & \\
\hline I & 0 & 0 & 0 & 0 & 2 \\
\hline II & 8 & 57.1 & 6 & 42.9 & 14 \\
\hline III & 23 & 79.3 & 6 & 20.7 & 29 \\
\hline IV & 5 & 100 & 3 & 60 & 5 \\
\hline \multicolumn{7}{|c|}{ Table 4. Comparison of TR in ECHO According to } \\
\hline
\end{tabular}

\section{DISCUSSION}

The cardiac manifestations of COPD are numerous. Impairment of right ventricular function and pulmonary blood vessels are well known to complicate the clinical course of COPD and co-relate inversely with survival. Pulmonary Arterial Hypertension (PAH) is the primary cardiovascular complication encountered in COPD. Chronic cor pulmonale is a strong predictor of death in COPD. Cor pulmonale is right ventricular enlargement secondary to pulmonary hypertension. Cor pulmonale can range clinically from mild changes in right ventricular function to frank right heart failure. Right ventricular dysfunction is reported to occur in up to $50 \%$ of the patients with moderate-to-severe COPD and portends a higher mortality rate. Its recognition and treatment may lead to prolonged survival and improved quality of life.[6] In our study, mean age was $59.52 \pm 12.53$ years. Female: male sex ratio was $1: 2.33$. So, COPD is more common in males and smokers in $5^{\text {th }}$ to 7 th decade of life.

The study group was divided into subgroups depending upon the duration of the disease. The duration of the disease was determined on the basis of retrospective history and any medical records available. Majority of patients in the study group fell in the disease duration group of $4-8$ years. The range of duration of disease was $4-20$ years with the mean duration being $11.08 \pm 4.83$ years. In study by Shreshta B et $\mathrm{al},[9]$ more than half of the COPD patients were in age group 60 - 75 years followed by less number of patients (approximately $20.0 \%$ ) in both 45 - 59 years and 75 - 89 years' age groups.

Most patients had moderate-to-severe disease at presentation. The study group was subdivided based on the severity of COPD according to GOLD guidelines. The group was divided into mild, moderate, severe and very severe COPD with $2 / 50=4 \%, 14 / 50=28 \%, 29 / 50=58 \%$ and $5 / 50=10 \%$ patients respectively. So there were very few patients in the study group falling in Stage I (mild COPD) showing that the patients with COPD usually present late in the illness. In study by Suma et al,[10] the number of patients with mild, moderate 
and severe COPD were $2 / 50=4 \%, 18 / 50=36 \%$ and $30 / 50=$ $60 \%$, respectively.

On analysis by echocardiography, there is high prevalence of cardiac dysfunction in COPD patients with tricuspid regurgitation and pulmonary arterial hypertension being the most common cardiac manifestations of COPD. PAH in ECHO in our study was present in $35 / 50=70 \%$ patients. Frequency of PAH in ECHO is mild, moderate, severe and very severe COPD was $0 / 2=0 \%, 7 / 14=50 \%, 23 / 29=79.3 \%$ and $5 / 5=$ $100 \%$, respectively. Tiwari et al, 2015[11] found that PAH was present in $51.6 \%$ of COPD patients and prevalence in mild, moderate, severe and very severe patients was $17 \%, 52 \%$, $60 \%$ and $78 \%$ respectively. The result of present study is comparable to previous studies. Statistical analysis of our study showed that the difference in the presence of PAH in different groups was statistically significant ( $p$ value $<0.05$, $p$ $=0.002$ ) and there is positive correlation (correlation coefficient +0.434 ) between severity of COPD and PAH, i.e. with increase in severity of COPD incidence of PAH increases. Thus, the incidence of $\mathrm{PAH}$ is directly proportional to severity of COPD.

In our study of total 50 patients, RV was enlarged in ECHO in $23 / 50=46 \%$ of patients. Frequency of RV enlargement in ECHO is mild, moderate, severe and very severe COPD was $0 / 2=0 \%, \quad 4 / 14=28.6 \%, \quad 14 / 29=48.3 \%$ and $5 / 5=100 \%$, respectively. Jain et al 2014[12] found that right ventricular dilatation was present in $66.7 \%$ of COPD patients and prevalence in mild, moderate, severe and very severe patients was $66.6 \%, 66.6 \%, 60 \%$ and $100 \%$ respectively. Tiwari et al, 2015 [11] found that cor pulmonale was present in $23.7 \%$ of COPD patients and prevalence in mild, moderate, severe and very severe patients was $12 \%, 15 \%, 40 \%$ and $44 \%$ respectively. So the present study is comparable to the previous studies. The present study also showed a statistically significant correlation between right ventricular enlargement and severity of COPD with spearman's correlation coefficient of +0.395 and $p$ value 0.005 . So as severity of COPD increases, incidence of RV enlargement also increases.

Out of total 50 patients, RA was enlarged in ECHO in 7/50 $=14 \%$ of patients. Frequency of RA enlargement in ECHO in mild, moderate, severe and very severe COPD was $0 / 2=0 \%$, $1 / 14=7.1 \%, 3 / 29=10.3 \%$ and $3 / 5=60 \%$, respectively. Jain et al 2014[12] found that right atrial enlargement was present in $50 \%$ of COPD patients and prevalence in mild, moderate, severe and very severe patients was $41.6 \%, 53.3 \%, 60 \%$ and $100 \%$ respectively. Our study also showed a statistically significant correlation between right atrial enlargement and severity of COPD with spearman's correlation coefficient of +0.307 and $p$ value 0.03 .

Out of total 50 patients, TR was present in ECHO in 36/50 $=72 \%$ of patients. Frequency of TR in ECHO in mild, moderate, severe and very severe COPD was $0 / 2=0 \%, 8 / 14=57.1 \%$, $23 / 29=79.3 \%$ and $5 / 5=100 \%$, respectively. Jain et al $2014[12]$ found that tricuspid regurgitation was present in $60 \%$ of COPD patients and prevalence in mild, moderate, severe and very severe patients was $58.3 \%, 60 \%, 60 \%$ and $100 \%$ respectively. Tiwari et al 2015[11] observed that tricuspid regurgitation was present in $74.2 \%$ of COPD patients. These findings were comparable to our study. The present study showed a statistically significant correlation between tricuspid regurgitation and severity of COPD with spearman's correlation coefficient of +0.387 and $p$ value 0.005 . So as severity of COPD increases, incidence of tricuspid regurgitation also increases.

\section{CONCLUSION}

The echocardiographic finding of pulmonary arterial hypertension, right ventricular enlargement, right atrial enlargement and tricuspid regurgitation positively correlated with severity of COPD as evidenced by echocardiographic finding of increased prevalence of these conditions with increasing severity of COPD. So prevalence of cardiac dysfunction increases as the severity of COPD increases and echocardiography helps in analysis of cardiac complications of COPD. It is recommended that echocardiography should be done early in all cases of COPD to diagnose the cardiac complications of COPD, so that early interventions can be undertaken in order to improve quality of life and decrease mortality and morbidity in COPD patients.

\section{REFERENCES}

1. Chesnutt MS, Prendergast TJ, Tavan ET. Pulmonary disorders. In: Papadakis MA, McPhee SJ, Rabow MW, edtr. CURRENT Medical Diagnosis \& Treatment. 53 ${ }^{\text {rd }}$ ed. New York: McGraw-Hill Education 2014:234-314.

2. Siafakas NM, Vermeire $P$, Pride NB, et al. Optimal assessment and management of chronic obstructive pulmonary disease (COPD). The European respiratory society task force. Eur Respir J 1995;8(8):1398-420.

3. Macnee W. Chronic bronchitis and emphysema. In: Seaton A, Seaton D, Leitch A, editors. Crofton and douglas's respiratory diseases. $5^{\text {th }}$ ed. vol 1. France: Blackwell Science 2002:p 616.

4. Anthonisen NR, Connett JE, Kiley JP, et al. Effects of smoking intervention and the use of an inhaled anticholinergic bronchodilator on the rate of decline of FEV1. The lung health study. JAMA 1994;272(19):1497505.

5. Sin DD, Anthonisen NR, Soriano JB, et al. Mortality in COPD: role of comorbidities. Eur Respir J 2006;28(6):1245-57.

6. Klinger JR, Hill NS. Right ventricular dysfunction in chronic obstructive pulmonary disease. Evaluation and management. Chest 1991;99(3):715-23.

7. Luke SH, Julia G, David D, et al. Echocardiographic assessment of pulmonary hypertension: standard operating procedure. Eur Respir Rev 2012;21(125):23948.

8. Daniels LB, Krummen DE, Blanchard DG. Echocardiography in pulmonary vascular disease. Cardiol Clin 2004;22(3):383-99.

9. Shrestha B, Dhungel S, Chokhani R. Echocardiography based cardiac evaluation in the patients suffering from chronic obstructive pulmonary disease. Nepal Med Coll J 2009;11(1):14-8.

10. Suma KR, Srinath S, Praveen. Electrocardiographic and echocardiographic changes in chronic obstructive pulmonary disease (COPD) of different grades of severity. Journal of Evolution of Medical and Dental Sciences 2015;4(30):5093-101.

11. Tiwari VK, Agarwal R, Kumar A, et al. The cardiac evaluation in chronic obstructive pulmonary disease patients. Indian Journal of Applied Research 2015;15(11):434-5.

12. Jain J, Soni P, Apte S, et al. A study of correlation between echocardiographic changes with the duration and severity of chronic obstructive pulmonary disease. Journal of Evolution of Medical and Dental Sciences 2014;3(8):19972002. 